\title{
Remodeling technique of aortic valve repair with root replacement and extraaortic ring
}

\section{Josip Varvodić*, Savica Gjorgjievska, Marko Kušurin, Mislav Planinc, Daniel Unić, Davor Barić, Robert Blažeković, Željko Sutlić, Igor Rudež}

University Hospital Dubrava, Zagreb, Croatia
RECEIVED:

August 28, 2017

ACCEPTED:

September 26, 2017

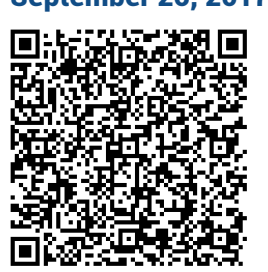

KEYWORDS: aortic valve, repair, root replacement.

CITATION: Cardiol Croat. 2017;12(9-10):369. | https://doi.org/10.15836/ccar2017.369

*ADDRESS FOR CORRESPONDENCE: Josip Varvodić, Klinička bolnica Dubrava, Avenija Gojka Šuška 6, HR-10000, Zagreb, Croatia. / Phone: +385-99-3553-909 / E-mail: josip.varvodic@gmail.com

ORCID:Josip Varvodić, http://orcid.org/0000-0001-6602-699X • Savica Gjorgjievska, http://orcid.org/0000-0002-4304-1852 Marko Kušurin, http://orcid.org/0000-0001-5690-9924 • Mislav Planinc, http://orcid.org/0000-0002-9833-832X Daniel Unić, http://orcid.org/0000-0003-2740-4067 • Davor Barić, http://orcid.org/0000-0001-5955-0275 Robert Blažeković, http://orcid.org/0000-0001-7125-361X • Željko Sutlić, http://orcid.org/0000-0001-6926-9436 Igor Rudež, http://orcid.org/0000-0002-7735-6721

IIIIIIIIIIIIIIIIIIIIIIIIIIIIIIIIIIIIIIIIIIIIIIIIIIIIIIIIIIIIIIIIIIIIIIIIIIIIIIIIIIIIIIIIIIIIIIIIIIIIIIIIIIIIIIIIIIIIIII

Objective: Aortic valve replacement (AVR) is still the most commonly used therapeutic option for patients suffering from AR. Aortic valve repair (AVRep) is an attractive alternative method, since it avoids the risks of prosthesis-related complications. ${ }^{1,2}$ We would like to present our experience with the Yacoub root remodeling, valve sparing technique with the extraaortic expansible ring.

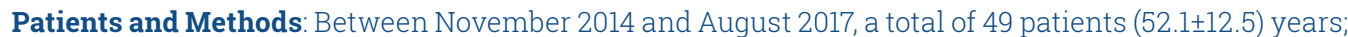
$18.9 \%$ female, EuroScore II of $(2.4 \% \pm 1 \%)$ underwent AVRep, 6 due to isolated cusp malcoaptation and 43 with associated with aortic root dilatation. Recontruction was done with the Coroneo Extraaortic Ring (27 (25-31)) and the Gelweave graft (28 (26-32)). Concomitant procedures included MVRep in three patients with TVrep in two of them, CABG in two patents and replacement of aortic arch and placement of EVITA stent graft in two patients. Echocardiography was used to determine AR severity grade pre-operatively, during immediate post-operative period (within 7 days from operation) and at early follow-up.

Results: In postoperative follow up no patients died. Freedom from reoperation was $94 \%(3 / 37)$ and there were 2 patients reoperated due to early postoperative regurgitation, and one because of early cardiac tamponade. A significant decrease in LV end-diastolic diameter was observed (LVEDD) (61.3/53.5 $\mathrm{mm}$ ) with further decrease at early follow-up. At follow up none of the patients had major AR (AR $0=40$, AR $1+=7$, AR 2+=2)

Conclusions: We have proved that AVRep is a good alternative for patients with aortic insufficiency and leads to LV reverse remodeling with comparable results in terms of LVEDD and LVEF immediately post-operatively and at early follow.
LITERATURE IIIIIIIIIIIIIIIIIIIIIIIIIIIIIIIIIIIIIIIIIIIIIIIIIIIIIIIIIIIIIIIIIIIIIIIIIIIIIIIIIIIIIIIIIIIIIIIIIIII 1. Lansac E, Di Centa I, Raoux F, Bulman-Fleming N, Ranga A, Abed A, et al. An expansible aortic ring for a physiological approach to conservative aortic valve surgery. J Thorac Cardiovasc Surg. 2009 Sep;138(3):718-24. https://doi.org/10.1016/j.jtcvs.2009.05.024

2. Lansac E, Di Centa I, Vojacek J, Nijs J, Hlubocky J, Mecozzi G, et al. Valve sparing root replacement: the remodeling technique with external ring annuloplasty. Ann Cardiothorac Surg. 2013 Jan;2(1):117-23. https://doi.org/10.3978/j.issn.2225-319x.2013.01.15 